(C) И.А.Козыро, А.В.Сукало, 2017

УДК 616.611-002-036.12-06-053.32

doi: $10.24884 / 1561-6274-2017-21-4-73-78$

И.А. Козыро, А.В. Сукало

ФАКТОРЫ ПРОГРЕССИРОВАНИЯ ВТОРИЧНЫХ ГЛОМЕРУЛОНЕФРИТОВ У ДЕТЕЙ

1-я кафедра детских болезней Белорусского государственного медицинского университета, г. Минск, Беларусь

I.A. Kozyro, A.V. Sukalo

\title{
FACTORS OF PROFGRESSION OF SECONDARY GLOMERULONEPHRITIS IN CHILDREN
}

1-st Department of children diseases Belarusian State Medical University, Minsk, Belarus

\section{РЕФЕРАТ}

В статье представлены современные знания о новых маркерах, применяемых для диагностики и мониторинга активности волчаночного и нефрита при геморрагическом и АНЦА-васкулитах у детей, что может быть использовано в практической работе нефролога для оптимизации проводимого лечения и определения его продолжительности.

Ключевые слова: люпус-нефрит, нефрит при геморрагическом васкулите, АНЦА-ассоциированный нефрит, дети, антитела, цитокины.

\section{ABSTRACT}

This article presents the modern data of the new markers for diagnostics and monitoring the activity of lupus nephritis at Henoch-Schoenlein purpura and ANCA vasculitis in children, which can be used in practice of nephrologists to optimize the treatment and determine its duration.

Key words: lupus nephritis, Henoch-Schoenlein purpura nephritis, ANCA-associated nephritis, children, antibodies, cytokines.

\section{ВВЕДЕНИЕ}

Системная красная волчанка (СКВ) и геморрагический васкулит Шенлейна-Геноха (ГВ) занимают лидирующие позиции среди системных вазопатий у детей. Поражение почек при СКВ, по данным световой микроскопии, варьирует, в среднем, от 50 до $70 \%$. Однако при использовании электронной микроскопии те или иные признаки поражения почек при СКВ удается обнаружить даже при отсутствии мочевого синдрома. При ГВ характерные черты гломерулопатии выявляют в $25-80 \%$ случаев.

На сегодняшний день не существует ни одного «универсального» специфического для волчаночного и нефрита при ГВ маркера, позволяющего проводить раннюю диагностику, мониторинг активности непосредственно нефрита, что указывает на необходимость поиска наиболее чувствительных и специфичных предикторов обострения почечного процесса для оптимизации лечения и прогноза при данном заболевании [6].

Козыро И.А. Республика Беларусь, г. Минск, 220116, пр. Дзержинского, д. 83. Белорусский государственный медицинский университет, 1-я кафедра детских болезней. E-mail: kozyroia@mail.ru
Целью нашего исследования явилось исследование факторов активации T-(CCL5/RANTES)- и B (BAFF)-лимфоцитов, провоспалительных медиаторов (Caspase-1, TNF $\alpha$, IL-1 $\beta$ ), маркеров сосудистых нарушений и прогрессирования фиброгенеза (VEGF, TGF- $\beta 1$ ) у детей с вторичными гломерулонефритами (ГН) [вследствие СКВ, люпуснефрита (ЛН), посткапилляротоксического (ПН) и нефрита при АНЦА-васкулите] и уточнение их вклада в развитие и прогрессирование вышеприведенной патологии.

\section{ПАЦИЕНТЫ И МЕТОДЫ}

Для выявления молекулярных медиаторов развития и прогрессирования ГН у детей проведен ИФА с использованием тест-систем R\&D Systems Quantikine ELISA: «Human CCL5/RANTES», «Human BAFF/BLys/TNFSF13B», «TNF $\alpha$ », «VEGF», «Human Caspase-1/ICE», «Human IL-

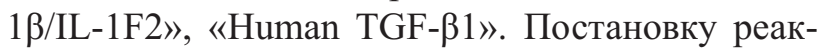
ций проводили в соответствии с инструкциями по применению прилагаемыми производителями (США, Канада). Учет результатов проводили на 
ИФА - анализаторе «АИФ-М/340» («Витязь», Республика Беларусь) при длине волны 450 нм.

Статистический анализ результатов выполняли с использованием пакета прикладных статистических программ «Microsoft Excel 2003» («Microsoft Corporation», США). Результаты представлены в виде среднего арифметического \pm ошибка средней. Статистическую значимость различий двух средних определяли с помощью t-критерия Стьюдента; частот $-\chi^{2}$-критерия Пирсона. Оценку силы взаимосвязи между количественными признаками проводили с помощью коэффициента корреляции (r) Пирсона. Нулевую статистическую гипотезу об отсутствии различий и связей отвергали при $\mathrm{p}<0,05$.

\section{РЕЗУЛЬТАТЫ}

Проведено обследование 106 пациентов с первичными и вторичными ГН, а также 36 условно здоровых детей группы контроля. Основную группу составили 40 пациентов с вторичными ГН вследствие СКВ, ЛН ( $\mathrm{n}=20)$, вторичным посткапилляротоксическим нефритом (ПН) вследствие геморрагического васкулита Шенлейна-Геноха $(\mathrm{n}=16)$, вторичным нефритом вследствие системного васкулита (СВ), гранулематоза Вегенеpa $(n=4)$. В группу сравнения вошли пациенты с $\operatorname{IgA-нефропатией~}(\mathrm{n}=21)$, нефропатией минимальных изменений $(\mathrm{n}=21)$, фокально-сегментарным гломерулосклерозом $(\mathrm{n}=21), \quad$ мезангиокапиллярным гломерулонефритом $(\mathrm{n}=3) .34$ пациента были обследованы динамически в процессе лечения. Возраст пациентов варьировал от 2 до 18 лет $(13,2 \pm 4,1$ года). Проведено клиниколабораторное, инструментальное, иммунологическое, вирусологическое обследование Выполнена гистологическая, иммуногистохимическая и электронно-микроскопическая оценка нефробиоптатов текущего $(n=106)$ и архивного $(27$ с ЛН и ПН) материала.

Результаты исследования регулятора активации нормальной Т-клеточной экспрессии и секреции CCL5/RANTES и фактора активации B-лимфоцитов BAFF в сыворотке крови пациен- тов с вторичными, первичными ГН и здоровых детей представлены в табл. 1.

У пациентов с CKB, ЛН концентрация CCL5/ RANTES в сыворотке крови составила 450-2000 ЕД (25-75\%, ДИ 495-755), медиана - 530, в среднем $747,0 \pm 106,8$. У пациентов с вторичным ПН CCL5/RANTES 470-1800 ЕД (25-75\%, ДИ 515-1220), медиана - 770, в среднем $921,3 \pm 114,1$, при поражении почек вследствие СВ концентрация CCL5/RANTES составила 520-2000 ЕД (25$75 \%$, ДИ 525-2000), медиана - 1265, в среднем $1263,0 \pm 425,8$ (рис. 1).

В период снижения активности патологического процесса (ремиссии) у пациентов с вторичными ГН происходило достоверное уменьшение концентрации CCL/RANTES (250-1500, ДИ 475500 , медиана 500 , в среднем $550,7 \pm 29,16)$ в сравнении с обострением ( $\mathrm{p}=0,0002)$, рис. 2 .

У пациентов с СКВ, ЛН концентрация BAFF в сыворотке крови составила 125-2000 ЕД (2575\%, ДИ 250-600), медиана - 425, в среднем $326 \pm 140,6$. У пациентов с вторичным ПН ВАFF в сыворотке крови 240-1000 ЕД (25-75\%, ДИ 325$625)$, медиана -435 , в среднем $515,6 \pm 67,5$, при поражении почек вследствие системного васкулита концентрация BAFF в сыворотке крови составила 400-1000 ЕД (25-75\%, ДИ 440-1000), медиана 740 , в среднем $720,0 \pm 162,5$ (рис. 3 ).

В период снижения активности патологического процесса (ремиссии) у пациентов с вторичными ГН происходило достоверное уменьшение концентрации BAFF (с 125-2000 до 110-1000 ЕД, ДИ 325-1000 до 250-370, медиана с 480 до 290, в среднем $631,5 \pm 75,97)$ в сравнении с обострением ( $\mathrm{p}=0,01)$ (рис. 4).

Показано участие факторов активации Т- и В-лимфоцитов (CCL/RANTES, BAFF) в развитии вторичных ГН в сравнении с контролем и группой первичных ГН. При вторичных ГН концентрация CCL/RANTES, BAFF коррелировала со степенью тяжести патологического процесса в почечной ткани: АГ, креатинином в сыворотке крови, выраженностью протеинурии и длительностью ее

Концентрация молекул активации RANTES и BAFF у детей с ГH

Таблица 1

\begin{tabular}{l|l|l|l|l|l}
\hline Группы & Медиаторы & Концентрация, ЕД & $25-75 \%$ ДИ & Медиана & М $\pm \mathrm{m}$ \\
\hline \multirow{2}{*}{ Вторичные ГП } & RANTES & $450-2000^{*}$ & $510-1200^{* *}$ & 535 & $868,3 \pm 82,42$ \\
\cline { 2 - 6 } & BAFF & $125-2000^{*}$ & $250-675$ & 440 & $589,9 \pm 79,4$ \\
\hline \multirow{2}{*}{ Первичные ГП } & RANTES & $125-1200^{* *}$ & $460-660$ & 500 & $550,7 \pm 29,16$ \\
\cline { 2 - 6 } & BAFF & $62,5-1200^{* *}$ & $200-417,5$ & 280 & $317 \pm 23,34$ \\
\hline & RANTES & $125-510^{*},{ }^{* *}$ & $365-480$ & 460 & $411,7 \pm 18,39$ \\
\cline { 2 - 6 } & BAFF & $62,5-300^{*},{ }^{* *}$ & $125-250^{* *}$ & 150 & $174,4 \pm 10,93$ \\
\hline
\end{tabular}

${ }^{*} p=0.0001 ;{ }^{* \star} p=0,0003$. 
ЛН-СВ-ПН

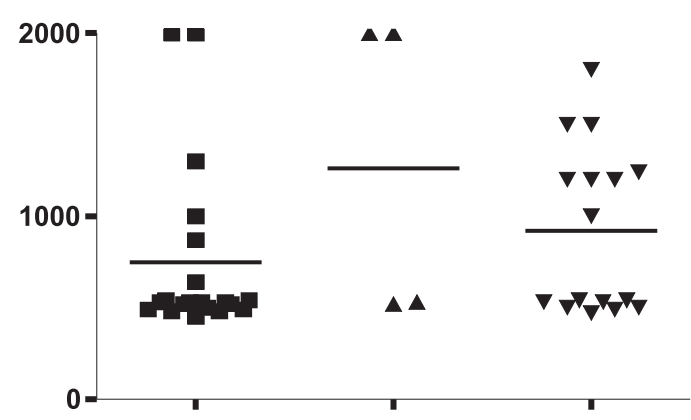

Рис. 1. Концентрация CCL/RANTES в сыворотке крови у пациентов с вторичными ГН.

\section{ЛН-СВ-ПН}

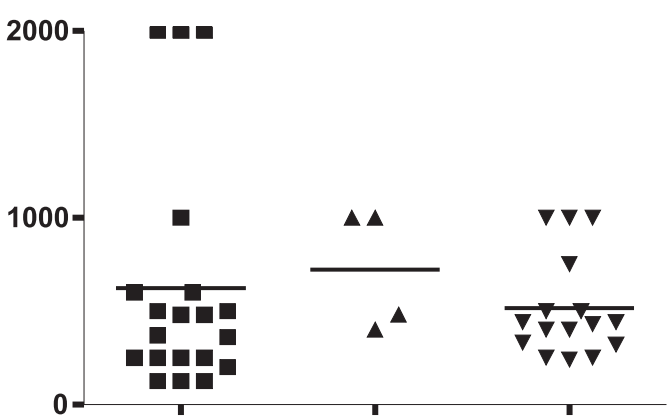

Рис. 3. Концентрация BAFF в сыворотке крови у пациентов с вторичными ГН.

Лн-СВ-Пн

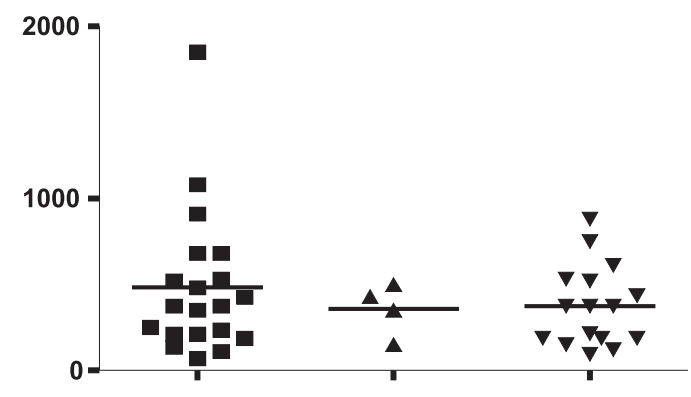

Рис. 5. Концентрация VEGF в сыворотке крови у пациентов с вторичными ГН.

ЛН-СВ-ПН

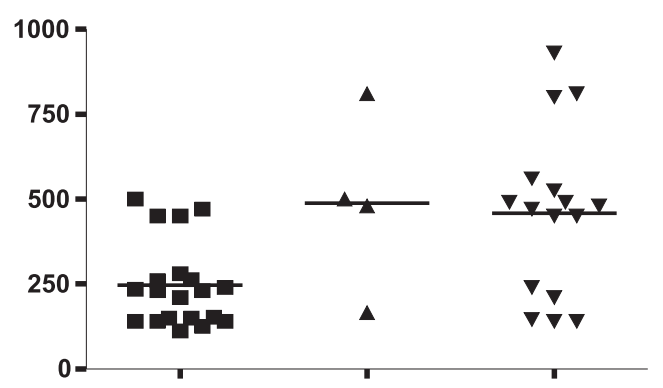

Рис. 7. Концентрация TGF-1 в сыворотке крови у пациентов с вторичными ГН.
Обострение-ремиссия. Вторичные ГП

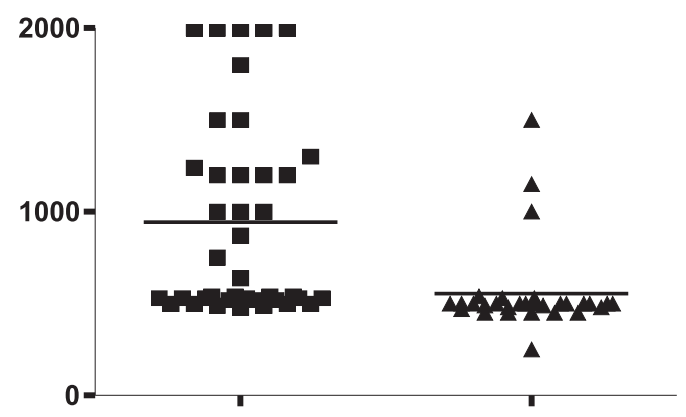

Рис. 2. Концентрация CCL/RANTES в сыворотке крови у пациентов с вторичными ГН в период активных проявлений и ремиссии.

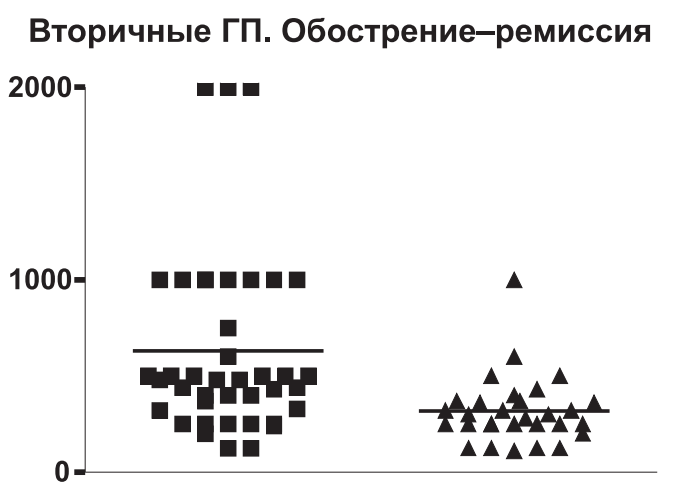

Рис. 4. Концентрация BAFF в сыворотке крови в периоды обострения и ремиссии у пациентов с вторичными ГН $(p=0,01)$.

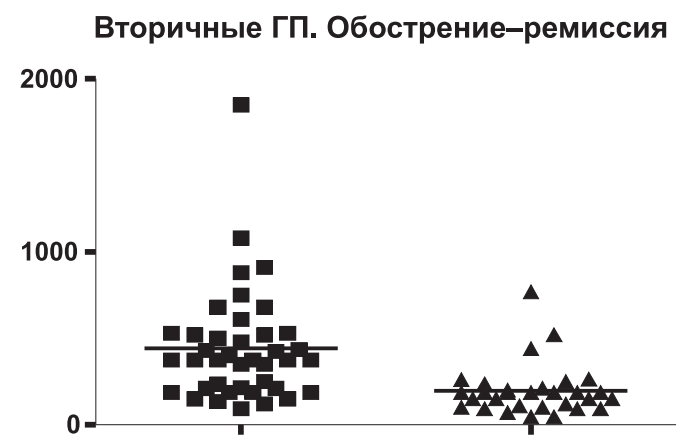

Рис. 6. Концентрация VEGF в сыворотке крови при обострении и ремиссии вторичных ГН.

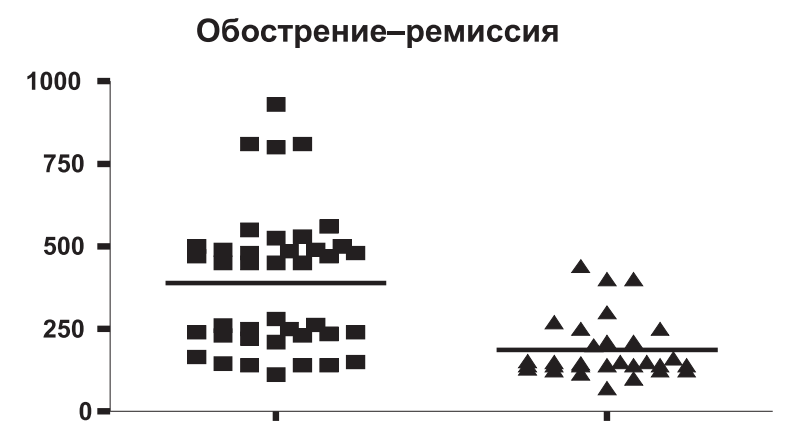

Рис. 8. Концентрация TGF-1 $1 \beta$ в сыворотке крови у пациентов с обострением и ремиссией ЛН и ПН. 
персистирования, гематурии, морфологическими и лабораторными признаками высокой активности ЛН и ПН. В случае положительной клиниколабораторной динамики отмечалось снижение вышеприведенных молекул и, наоборот, при развитии обострения заболевания концентрация CCL/RANTES и BAFF повышалась, что позволяет использовать их в клинической практике в качестве дополнительных иммунологических маркеров для диагностики и оценки эффективности проводимой патогенетической терапии.

Результаты определения концентрации сосудистого фактора роста VEGF и профибротического фактора роста TGF-1 $\beta$ приведены в табл. 2 .

У пациентов с CKВ, ЛН концентрация VEGF в сыворотке крови составила 70-1850 ЕД (25-75\%, ДИ 210-605), медиана - 375, в среднем 483,2士93,4. У пациентов с вторичным ПН концентрация VEGF 93,8-880 ЕД (25-75\%, ДИ 188-525), медиана 375 , в среднем $374,6 \pm 58,6$, при СВ концентрация VEGF в сыворотке крови составила 150-500 ЕД (25-75\%, ДИ 250-465), медиана - 390, в среднем $357,5 \pm 75,7$ (рис. 5)

В период снижения активности патологического процесса (ремиссии) у пациентов с вторичными ГП происходило достоверное уменьшение концентрации VEGF (с 93,8-1850 до 46,9-770 ЕД, ДИ 210-525 до 100-222,5, медиана с 375 до 188, в среднем от $442 \pm 51,3$ до $198 \pm 27,1)$ в сравнении с обострением $(\mathrm{p}=0,01)$ (рис. 6).

$\mathrm{y}$ пациентов с ЛН концентрация TGF-1 $\beta$ в сыворотке крови составила 112,0-500,0 ЕД (25$75 \%$, ДИ 145-271,5), медиана - 230, в среднем $246,4 \pm 27,9$, с вторичным ПН TGF-1 $\beta$ в сыворотке 140,0-930,0 ЕД (25-75\%, ДИ 225-542,5), медиана -475 , в среднем $458,1 \pm 60,9$, с СВ концентрация TGF-1 $\beta$ 165-810,0 ЕД (25-75\%, ДИ 322,5-655), медиана - 490,0, в среднем 488,8 $8 \pm 131,7$ (рис. 7).

В период снижения активности патологического процесса (ремиссии) у пациентов с вторичными ГП происходило достоверное уменьшение концентрации TGF-1 $\beta$ (с 112-930 до 70-440 ЕД, ДИ от 230-495 до 135-230, медиана с 450 до $147,5$, в среднем от $389,5 \pm 33,01$ до $186,9 \pm 16,9)$ в сравнении с обострением ( $\mathrm{p}=0,001)$, рис. 8 .

У пациентов с вторичными ГП (ЛН, ПН) и ФСГС концентрация профибротических факторов роста коррелировала с клиническими (уровнем сывороточного креатинина, АГ, выраженностью протеинурии) и морфологическими признаками тяжести патологического процесса (гиперклеточность клубочков с сегментарным некрозом, сегментарный ГС с наличием спаек, наличие субэндотелиальных эозинофильных депозитов, процент тотально склерозированных клубочков, фиброклеточных и фиброзных полулуний, утолщение стенок сосудов и периваскулярной инфильтрацией), а также формированием резистентности к проводимой терапии. Исследование VEGF у пациентов с ЛН, ПН и ФСГС в динамике позволяет прогнозировать течение вторичных ГП и ФСГС.

Результаты определения молекулярных медиа-

Концентрация факторов роста VEGF и TGF-1及 у пациентов с ГH

Таблица 2

\begin{tabular}{l|l|l|l|l|l}
\hline Группы & Медиаторы & Концентрация, ЕД & $25-75 \%$ ДИ & Медиана & М $\pm \mathrm{m}$ \\
\hline \multirow{2}{*}{ Вторичные ГП } & VEGF & $70-1850^{*}$ & $188-525$ & 375 & $427,1 \pm 52,7$ \\
\cline { 2 - 6 } & TGF-1 $\beta$ & $112-930^{*}$ & $151,5-485$ & 261,5 & $355,3 \pm 34,6$ \\
\hline \multirow{2}{*}{ Первичные ГП } & VEGF & $23,4-1200$ & $110-237,5$ ** & 150 & $225,7 \pm 29,9$ \\
\cline { 2 - 6 } & TGF-1 $\beta$ & $62,5-820,0$ & $150-400^{* *}$ & 245 & $277,3 \pm 19,2$ \\
\hline \multirow{2}{*}{ Здоровые дети } & VEGF & $23,4-415^{*}$ & $125-215^{* *}$ & 127,5 & $157 \pm 12,9$ \\
\cline { 2 - 6 } & TGF-1 $\beta$ & $31,2-180^{*}$ & $120-150$ ** & 140 & $130,9 \pm 4,9$ \\
\hline
\end{tabular}

${ }^{\star} p=0,0001,{ }^{* \star} p=0,001$.

Концентрация провоспалительных цитокинов каспазы-1, IL-1ß, TNF $\alpha$ у детей с ГH

\begin{tabular}{|c|c|c|c|c|c|}
\hline Группы & Медиаторы & Концентрация, ЕД & 25-75\% ди & Медиана & $\mathrm{M} \pm \mathrm{m}$ \\
\hline \multirow[t]{3}{*}{ Вторичные ГП } & Каспаза-1 & $25-400$ * & $90-365$ & 220 & $215,3 \pm 22,2$ \\
\hline & IL-1 $1 \beta$ & $15,6-95$ * & $15,6-31,3$ & 28,5 & $34,2 \pm 3,4$ \\
\hline & TNF $\alpha$ & $25-125$ * & $40,0-67,5$ & 60 & $60,09 \pm 4,3$ \\
\hline \multirow[t]{3}{*}{ Первичные ГП } & Каспаза-1 & $300-400$ & $80-250$ ** & 120 & $169,7 \pm 14,9$ \\
\hline & IL-1 $\beta$ & $3,9-85,0$ & $10-25^{* *}$ & 15,6 & $18,6 \pm 1,6$ \\
\hline & TNF $\alpha$ & $15,6-85,0$ & $20-47,5^{\star *}$ & 31,2 & $37,3 \pm 2,3$ \\
\hline \multirow[t]{3}{*}{ Здоровые дети } & Каспаза-1 & $12,5-100$ * & $45-70$ ** & 50 & $52,57 \pm 3,9$ \\
\hline & IL-1 $\beta$ & $3,9-31,2$ * & $7,3-16,3^{\text {** }}$ & 13,8 & $12,84 \pm 1,2$ \\
\hline & TNF $\alpha$ & $15,6-62,5^{*}$ & $31,2-42,5^{\text {** }}$ & 40 & $37,9 \pm 2,03$ \\
\hline
\end{tabular}

${ }^{*} p<0,005$. 
ЛН-СВ-ПН

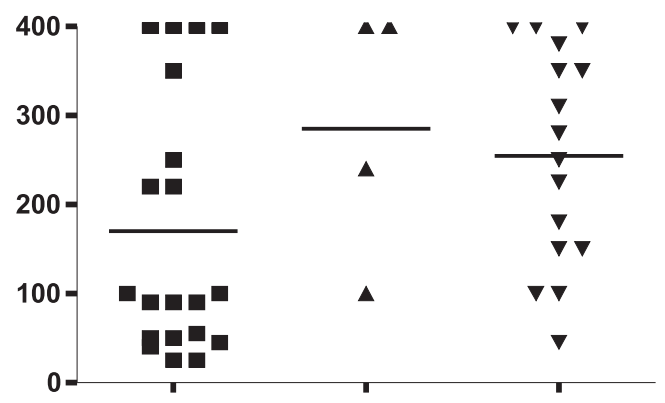

Рис. 9. Концентрация каспазы-1 в сыворотке крови при вторичныхГП.

\section{ЛН-СВ-ПН}

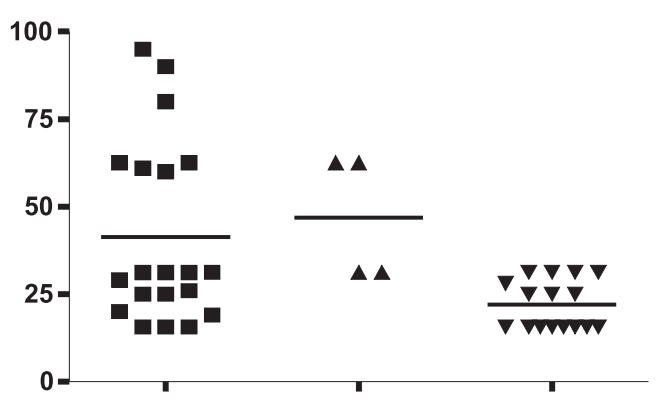

Рис. 11. Концентрация IL- $1 \beta$ в сыворотке крови у детей с ЛН, $\mathrm{CB}, \mathrm{\Pi H}$.

\section{ЛН-СВ-ПН}

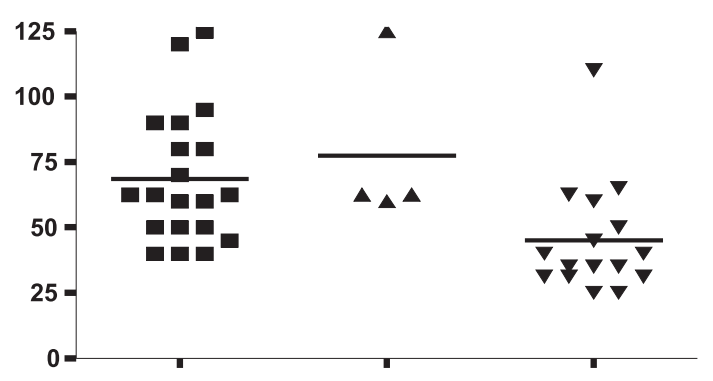

Рис. 13. Концентрация TNF $\alpha$ в сыворотке крови при вторичных ГП.

торов - провоспалительных цитокинов каспазы-1, IL-1 $\beta$, TNF $\alpha$ представлены в табл. 3.

У пациентов с ЛН концентрация каспазы в сыворотке крови составила 25-400 ЕД (25-75\%, ДИ 50-300), медиана - 95, в среднем $170 \pm 32,3$, с вторичным ПН концентрация каспазы составила 45-400 ЕД (25-75\%, ДИ 150-365), медиана - 265, в среднем $254,4 \pm 30,4$, с СВ 100-400 ЕД (25-75\%, ДИ 170-400), медиана - 320, в среднем 285 $\pm 72,3$ (рис. 9).

В период снижения активности патологического процесса (ремиссии) у пациентов с вторичными ГП происходило достоверное уменьшение концентрации каспазы (с 25-400 до 45-400 ЕД, доверительный интервал от 100-400 до 75-235, медиана

\section{Вторичные ГП. Обострение-ремиссия}

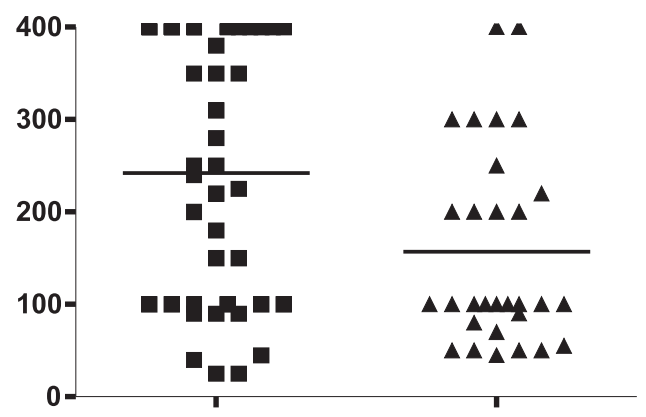

Рис. 10. Концентрация каспазы-1 в сыворотке крови при обострении и ремиссии у пациентов с вторичными гломерулопатиями.

\section{Вторичные ГП. Обострение-ремиссия}

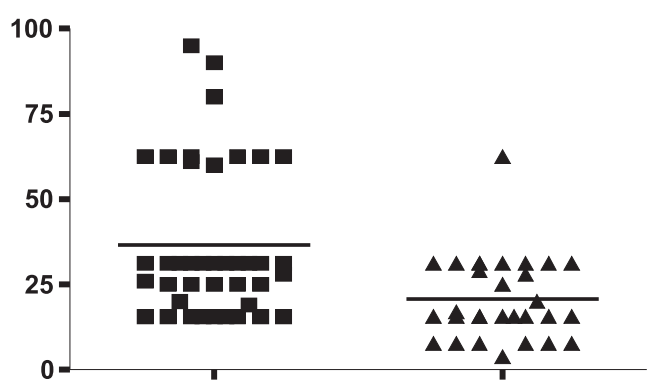

Рис. 12. Концентрация IL-1 $\beta$ в сыворотке крови при обострении и ремиссии вторичных ГП.

\section{Вторичные ГП. Обострение-ремиссия}

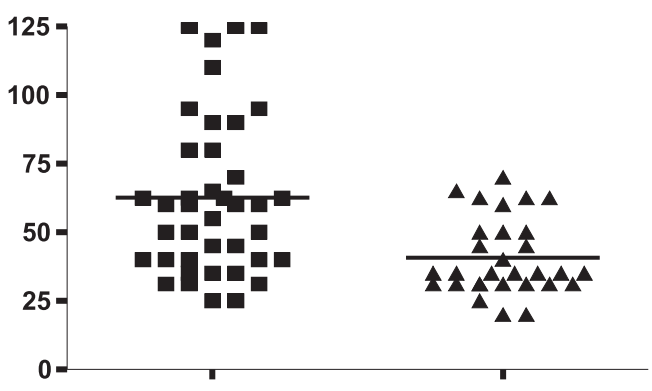

Рис. 14. Концентрация TNF $\alpha$ в сыворотке крови при вторичных ГП в периоды обострения и ремиссии.

с 245 до 100 , в среднем $242,3 \pm 21,9$ до $157 \pm 19,6)$ в сравнении с обострением ( $\mathrm{p}=0,007)$, рис. 10.

У пациентов с ЛН концентрация IL-1 $\beta$ в сыворотке крови составила 15,6-95,0 ЕД (25-75\%, ДИ

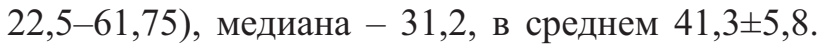
У пациентов с вторичным ПН IL-1 $\beta$ в сыворотке крови 15,6-31,3 ЕД (25-75\%, ДИ 15,6-29,6), медиана $-20,3$, в среднем $22,04 \pm 1,7$. У детей с нефритом вследствие CB концентрация IL-1 $\beta$ 31,2-62,5 ЕД (25-75\%, ДИ 31,25-62,5), медиана 46,9, в среднем $46,9 \pm 9$ (рис. 11 ).

В период снижения активности патологического процесса (ремиссии) у пациентов с вторичными ГП происходило достоверное уменьшение концен- 
трации IL-1 $\beta$ (с 15,6-95,0 до 3,9-62,5 ЕД, доверительный интервал 19,5-60,5 до 11,7-31,2, медиана с 31,2 до 15,6 , в среднем $36,6 \pm 3,5$ до $20,7 \pm 2,2$ ) в сравнении с обострением ( $\mathrm{p}=0,007)$ (рис. 12).

У пациентов с СКВ, ЛН концентрация TNF $\alpha$ в сыворотке крови составила 40,0-125,0 ЕД (25-75\%, ДИ 50-85), медиана - 62,5, в среднем $68,6 \pm 5,6$. У пациентов с вторичным ПН TNF $\alpha$ в сыворотке 25,0-110,0 ЕД (25-75\%, ДИ 31,2-37,5), медиана $-37,5$, в среднем $45,07 \pm 5,4$. У детей с $\mathrm{CB}$ TNF $\alpha$ в сыворотке крови 60-125,0 ЕД (25$75 \%$, ДИ 61,25-93,75), медиана - 62,5, в среднем $77,5 \pm 15,8$ (рис. 13 ).

В период снижения активности патологического процесса (ремиссии) у пациентов с вторичными ГП происходило достоверное уменьшение концентрации TNF $\alpha$ (с 25,0-125 до 20-70 ЕД, доверительный интервал 40-80 до 31,2-50,0, медиана с 60 до 35, в среднем $62,6 \pm 4,6$ до $40,7 \pm 2,5)$ в сравнении с обострением ( $\mathrm{p}=0,003)$ (рис. 14).

У пациентов с вторичными ГП выявлено достоверное увеличение концентрации каспазы- 1 , $\mathrm{IL}-1 \beta$ и $\mathrm{TNF} \alpha(\mathrm{p}<0,05)$ в сравнении со здоровыми. В группах пациентов с вторичными ГП концентрация провоспалительных цитокинов коррелировала со степенью тяжести патологического процесса в почечной ткани (выраженностью протеинурии, гематурии, уровнем сывороточного креатинина, АГ, морфологическими и лабораторными признаками высокой активности ЛН и ПН).

Установленное достоверное увеличение концентрации провоспалительных цитокинов каспазы- 1 , IL-1 $\beta$, TNF $\alpha$ у пациентов с вторичными ГП $(p<0,05)$ по сравнению с контролем и группой сравнения, а также изменение концентрации вышеприведенных цитокинов в процессе лечения или, наоборот, развития рецидива болезни свидетельствует об их участии в патогенезе ЛН, ПН и нефрита при системном васкулите, что позволяет использовать их в качестве дополнительных критериев в диагностике и оценке адекватности проводимой терапии.

\section{ЗАКЛЮЧЕНИЕ}

Показано участие факторов активации Т- и В-лимфоцитов (CCL/RANTES, BAFF), профибротических факторов роста (TGF-1 $\beta, \mathrm{VEGF})$ и провоспалительных цитокинов (каспазы- 1 , IL-1 $\beta$, $\mathrm{TNF} \alpha$ ) в развитии вторичных ГП, их корреляция со степенью тяжести патологического процесса в почечной ткани, а также изменение концентрации вышеприведенных молекул в случае обострения или ремиссии, что позволяет использовать их в клинической практике в качестве дополнительных иммунологических маркеров для диагностики и оценки эффективности проводимой патогенетической терапии.

\section{БИБЛИОГРАФИЧЕСКИЙ СПИСОК}

1. Salgado A, Herrera-Diaz C. Lupus nephritis: an overview of recent findings. Autoimmune disease, Volume 2012, Article ID $849684,21 \mathrm{p}$

2. Jordan N, Lutalo PM, D'Cruz DP. Novel therapeutic agents in clinical development for Systemic Lupus Erythematosus. BMC Medicine 2013; 3 11(1):120

3. Niaudet P, Salomon R. Systemic Lupus Erythematosus. In: E.D Avner, W.E. Harmon, P Niaudet. Pediatric Nephrology, 5th ed. Philadelphia: Lippincott Williams\&Wilkins, 2004; 865-886

4. Rees L. In L. Rees, N. Webb, P. Brogan. Paediatric nephrology, London: Oxford University Press, 2007; 282-296

5. Avramescu C, Biciusca V, Daianu T. et al. Cytokine panel and histopathological aspects in the systemic lupus erythematosus. Romanian journal of Morphology and Embryology 2010; 51(4): 633-640

6. Brunner HI, Bennett MR, Mina R et al. Association of noninvasively measured renal protein biomarkers with histologic features of lupus nephritis. Arthritis Rheum 2012 Aug;64(8):2687-2697

7. Edelbauer M, Kshirsagar S, Riedl M et al. Markers of childhood lupus nephritis indicating disease activity. Pediatr Nephrology 2011; 26:401-410

8. Vachvanichsanong P, McNeil E. Pediatric lupus nephritis: more options, more chances? Lupus 2013; 22(6):545-553

9. Watson L, Beresford M. Urine biomarkers in juvenile-onset SLE nephritis. Pediatr Nephrol 2013; 28(3): 363-374

10. Vincent FB, Saulep-Easton D, FeggettWA et al. The BAFF/ APRIL system: emerging functions beyond $B$ cell biology and autoimmunity. Cytokine Growth Factor Rev 2013 Jun;24(3):203-215

11. Козыро ИА, Сукало АВ. Новые маркеры в диагностике люпус-нефрита у детей (обзор литературы). Нефрология 2015;19 (3):39-43 [Kozyiro IA, Sukalo AV. Novyie markeryi v diagnostike lyupus-nefrita u detey (obzor literaturyi).Nefrologiya 2015;19 (3):39-43

\section{Сведения об авторах:}

Доц. Инна Александровна Козыро, канд. мед. наук Республика Беларусь, г. Минск, 220116, пр. Дзержинского, д. 83. Белорусский государственный медицинский университет, 1-я кафедра детских болезней. E-mail: kozyroia@mail.ru Associate professor Inna A. Koziro, MD, PhD,

Affiliations: Republic Belarus, Minsk 220116, Dzerzhinski Ave., 83 Belarusian State Medical University First Department of children diseases. E-mail: kozyroia@mail.ru

Проф., академик Александр Васильевич Сукало, д-р мед.наук Республика Беларусь, г. Минск, 220116, пр. Дзержинского, д. 83. Белорусский государственный медицинский университет, 1-я кафедра детских болезней. Заведующий, зам. Председателя Президиума Национальной академии наук Беларуси. Academic Alexandr V. Sukalo, MD, PhD, DMedSci

Affiliaton: Republic Belarus, Minsk 220116, Dzerzhinski Ave., 83 Belarusian State Medical University First Department of children diseases, Chief, Deputy Chairman of the Presidium of the Belarus National Academy of Sciences.

Авторы заявляют об отсутствии конфликта интересов.

Поступила в редакцию: 10.12 .16 г Принята в печать: 06.06 .17 г. 